Article

\title{
Optimal Adherence to a Mediterranean Diet May Not Overcome the Deleterious Effects of Low Physical Fitness on Cardiovascular Disease Risk in Adolescents: A Cross-Sectional Pooled Analysis
}

\author{
César Agostinis-Sobrinho ${ }^{1,2,3}$ (1) , Rute Santos ${ }^{2,4}$, Rafaela Rosário ${ }^{5}$, Carla Moreira ${ }^{2}$ (D), \\ Luís Lopes 2 (D), Jorge Mota ${ }^{2}$, Arvydas Martinkenas ${ }^{3}$, Antonio García-Hermoso 6 (iD, \\ Jorge Enrique Correa-Bautista ${ }^{7}$ and Robinson Ramírez-Vélez ${ }^{7, * \text { (iD }}$ \\ 1 School of Physical Education, Physiotherapy and Dance, Federal University of the South of Brazil, \\ Porto Alegre 91501-970, Brazil; cesaragostinis@hotmail.com \\ 2 Research Centre in Physical Activity, Health and Leisure, Faculty of Sport, University of Porto, \\ 4200450 Porto, Portugal; rutemarinasantos@hotmail.com (R.S.); carla_m_moreira@sapo.pt (C.M.); \\ luis.iec.um@hotmail.com (L.L.); jmota@fade.up.pt (J.M.) \\ 3 Faculty of Health Sciences, Klaipeda University, LT-91274 Klaipeda, Lithuania; Arvydas.Martinkenas@ku.lt \\ 4 Early Start Research Institute, Faculty of Social Sciences, School of Education, University of Wollongong, \\ Wollongong, NSW 2522, Australia \\ 5 School of Nursing, Research Centre in Child Studies, University of Minho, 4710 Braga, Portugal; \\ rrosario@ese.uminho.pt \\ 6 Laboratorio de Ciencias de la Actividad Física, el Deporte y la Salud, Facultad de Ciencias Médicas, \\ Universidad de Santiago de Chile, USACH, Santiago 7500618, Chile; antonio.garcia.h@usach.cl \\ 7 Centro de Estudios Para la Medición de la Actividad Física CEMA, \\ Escuela de Medicina y Ciencias de la Salud, Universidad del Rosario, Bogotá 111221, Colombia; \\ jorge.correa@urosario.edu.co \\ * Correspondence: robin640@hotmail.com or robinson.ramirez@urosario.edu.co; \\ Tel.: +57-1-297-0200 (ext. 3428)
}

Received: 22 May 2018; Accepted: 22 June 2018; Published: 25 June 2018

\begin{abstract}
To examine the combined association of cardiorespiratory fitness (CRF), muscular fitness (MF), and adherence to a Mediterranean diet (MeDiet) on cardiovascular risk in adolescents, a pooled study, including cross-sectional data from two projects [2477 adolescents (1320 girls) aged 12-18 years], was completed. A shuttle run test was used to assess CRF. MF was assessed by the standing-long jump and handgrip tests. Adherence to a MeDiet was assessed by the Kidmed questionnaire. A cardiovascular risk score was computed from the following components: Age and sex, waist circumference, triglycerides, systolic blood pressure, high-density lipoprotein cholesterol (HDL), and glucose. Analysis of covariance showed that participants classified as having optimal (High) adherence to a MeDiet/HighMF/HighCRF, as well those classified as low adherence to a MeDiet/HighMF/HighCRF, had, on average, the lowest cardiovascular risk score $(\mathrm{F}=15.6 ; p<0.001)$. In addition, the high adherence to a MeDiet/LowMF/LowCRF group had the highest odds of having a high cardiovascular risk (OR $=7.1 ; 95 \% \mathrm{CI}: 3.4-15.1 ; p<0.001)$, followed by the low adherence to a MeDiet/LowMF/LowCRF group (OR = 3.7; 95\% CI: 2.2-6.3; $p<0.001$ ), high adherence to a MeDiet/HighMF/LowCRF group (OR = 3.1; 95\% CI: 1.4-7.0; $p=0.006)$, and low adherence to a MeDiet/LowMF/HighCRF group (OR $=2.5 ; 95 \%$ CI: $1.5-4.4 ; p=0.002$ ) when compared to those with high adherence to a MeDiet/HighMF/HighCRF, after adjustments for potential confounders. In conclusion, our findings showed that, regardless of the MeDiet status, adolescents with low MF and low CRF cumulatively, presented the highest cardiovascular disease risk. Therefore, these findings suggest that the combination of these two fitness components may be beneficial to adolescents cardiometabolic profile, independent of MeDiet behaviour.
\end{abstract}


Keywords: cardiometabolic health; diet patterns; aerobic fitness; muscular strength; youth

\section{Introduction}

Cardiometabolic disorders in children and adolescents are occurring progressively at early ages worldwide [1]. From a public health perspective, this is of great concern due to the tracking of childhood metabolic syndrome into adulthood [2]. The most accepted cardiometabolic risk factors during childhood and adolescence are triglycerides, blood pressure, high-density lipoprotein cholesterol (HDL), total cholesterol (TC), waist circumference, and insulin resistance [3,4].

Adolescence is a crucial period in life for the adoption of lifestyle patterns that are likely to track into their adulthood and, because many chronic diseases that appear in adulthood have their roots in childhood, it is important for youth to establish healthy habits early in life. Although a number of non-modifiable factors influence cardiometabolic health, it can be improved with healthful dietary habits and ideal levels of physical activity during childhood and adolescence [5]. Unfortunately, there is well-documented evidence on poor diet quality [6-8], inadequate physical activity levels $[9,10]$, and the increase in the prevalence and severity of metabolic syndrome [11] in early ages.

Physical fitness is recognized as an independent predictor of cardiovascular disease (CVD) and adulthood mortality [12,13]. Physical inactivity and low physical fitness levels, particularly cardiorespiratory fitness (CRF) [14-16] and muscular fitness (MF) [17,18], have been associated with cardiovascular risk factors in adolescents, such as insulin resistance, obesity, high blood pressure, and lipid disorders, among others.

Studies in adolescents have investigated the association of individual physical fitness elements with cardiovascular risk factors $[15,16,19]$. Oftentimes, both MF and CRF have been mainly treated as an independent variable $[19,20]$ and only a few studies have investigated the combination of both components $[21,22]$.

A growing body of evidence strongly supports the assumption that an adherence to a Mediterranean diet pattern may reduce the risk of cardiometabolic and non-communicable diseases from early ages [23]. The Mediterranean diet (MeDiet) is characterized by being poor in saturated fat and rich in natural antioxidants, based on the consumption of fish, vegetables, fruits, legumes, olive oil, and nuts [23]. Previous studies have shown a positive relationship between an adherence to the MeDiet and cardiovascular health in adolescents [24].

Although the effect of MeDiet, CRF, and MF have already been individually associated to cardiometabolic outcomes, the influence of the combination of these three health determinants remain unknown in adolescents. To our knowledge, there are no data on the combined effect of CRF, MF, and MeDiet on cardiovascular health during adolescence. In this sense, considerable effort and attention are needed to improve the understanding of the combination of these health determinants on cardiovascular health in adolescents. In this context, the present study aimed to examine the combined association of $\mathrm{CRF}, \mathrm{MF}$, and adherence to a MeDiet on cardiovascular disease risk in adolescents.

\section{Methods}

\subsection{Study Design, Sampling Procedures, and Participants}

A relatively large-scale study (FUPRECOL study, in Spanish-Asociación de la fuerza prensil con manifestaciones de riesgo cardiovascular tempranas en niños y adolescentes colombianos) $[25,26]$ with 1948 adolescents was used and we then complemented this data with another similar project with adolescents of the same age (LabMed Study [25]) to increase the sample size for optimal adherence to a MedDiet (i.e., combined groups with CRF and MF), which is the main focus of this paper. Therefore, the current report is part of two studies: (1) The "Longitudinal Analysis of Biomarkers and Environmental Determinants of Physical activity (LabMed Physical Activity Study)", a school-based 
prospective cohort study carried out in four Portuguese cities from the North Region in adolescents from 12-18 years old. Detailed descriptions of the sampling and recruitment approaches and data collection have been described elsewhere in detail $[27,28]$. The LabMed Physical Activity Study was conducted in accordance with the Helsinki Declaration for Human Studies and was approved by the Portuguese Data Protection Authority (\#1112434/2011) and the Portuguese Ministry of Science and Education (0246200001/2011); and (2) The FUPRECOL Study is a cross-sectional study that seeks to establish the general prevalence of CVD risk factors (anthropometric, adiposity, metabolic, and genetic markers) in the study population (children and adolescents aged 9 to 17.9 years living in Bogota, Colombia). The FUPRECOL was approved by the institutional review board for the use of human subject research in addition to the Rosario University Board (Code CEI-ABN026-000262). The protocol was in accordance with the current Colombian laws governing clinical research on human subjects (Resolution 008430/1993 of the Ministry of health). Detailed descriptions of the sampling and recruitment approaches and data collection have been described elsewhere $[25,26]$.

For the present pooled analysis study, we include 2477 adolescents: 529 were from the LabMed study (267 girls, 262 boys, mean age $14.3 \pm 1.7$ years), and 1948 from the FUPRECOL study (1053 girls, 895 boys, mean age $14.2 \pm 1.5$ years). In the current paper, we include only the adolescents that have completed the same tests and methodological approaches for MF, CRF, diet pattern, pubertal stage, and all cardiometabolic variables.

\subsection{Adherence to the Mediterranean Diet}

The adherence to the MeDiet was assessed using the Kidmed index (Mediterranean Diet Quality Index for children and adolescents) [29]. The index is based on a 16-question, self-administered questionnaire, which sustain the principles of the Mediterranean dietary patterns, as well as those that undermine it. The final results of the index varied between 0 and 12 points. A value of 1 was given to the questions which have a positive connotation in accordance to the MeDiet $(+1)$. Participants were classified into the follow three levels: (1) $\leq 3$, very low diet quality; (2) 4-7, improvement needed to adjust intake to Mediterranean patterns; (3) $\geq 8$, optimal (High) adherence to the Mediterranean diet. To further analyses, we grouped level 2 and 1 and this group was classified as Low Adherence to a MeDiet.

\subsection{Cardiorespiratory Fitness}

CRF was assessed using the 20-m shuttle run test as previously described elsewhere [30]. Participants were asked to run back and forth between two parallel lines spaced $20 \mathrm{~m}$ apart, following the pace of an audio signal that began at a speed of $8.5 \mathrm{~km} / \mathrm{h}$ and increased by $0.5 \mathrm{~km} / \mathrm{h}$ at 1-min intervals. The maximum oxygen consumption $\left(\mathrm{VO}_{2} \mathrm{max}, \mathrm{mL} / \mathrm{kg} / \mathrm{min}\right.$ ) was estimated from the number of laps performed using the equation reported by Leger et al. [30]. The participants were also classified into two CRF groups (low and high) in accordance with the proposed cut-off for this population by Ruiz et al. [19].

\subsection{Muscular Fitness}

We used a handgrip dynamometer, (T.K.K. 5001, Grip-A, Takei, Japan), adjusted by sex and hand size for each adolescent, to assess the upper body isometric strength (handgrip strength test). The adolescents were instructed to stand with their arms completely extended, squeezing gradually and continuously on the handgrip, up to the maximum of their strength, for at least $2 \mathrm{~s}$, performing the test twice and alternating with both hands. A rest period of 90-s was given between trials. The best score for each hand was recorded in kilograms [31]. The handgrip score $(\mathrm{kg})$ was calculated as the average of the left and right and then expressed per kilogram of body weight [28].

To assess the lower body explosive strength, the standing long jump test was performed in an indoor wood floor gymnasium and the adolescents were instructed to jump from the starting line and to push off vigorously and jump as far forward as possible, landing on both feet, and staying upright. The participants performed the test twice and the best jump was recorded. The standing jump score was determined by the distance between the last heel-mark and the take-off line [31]. 
To create the muscular fitness score, the results of the handgrip strength and standing long jump tests were transformed into Z-scores by sex and age for the whole sample and then the sum of both tests was performed. Participants were divided into two groups: High MF group (second and third tertiles) and Low MF group (first tertile) [28].

\subsection{Data Management}

Eight exclusive groups were created according of the adherence to a MeDiet (Low and High), CRF group (Low and High), and MF (Low and High): (1) Low-MeDiet with LowMF/ LowCRF; (2) Low-MeDiet with HighMF/LowCRF; (3) Low-MeDiet with LowMF/HighCRF; (4) Low-MeDiet with HighMF/HighCRF; (5) High-MeDiet with LowMF/LowCRF; (6) High-MeDiet with HighMF/LowCRF; (7) High-MeDiet with LowMF/HighCRF; and (8) High-MeDiet with HighMF/HighCRF.

\subsection{Cardiometabolic Variables}

As previously described elsewhere [27,32], blood samples (triglycerides, HDL-C, glucose) and blood pressure were collected after an overnight fast $(>10 \mathrm{~h})$ and blood samples were collected according to standardized procedures. All assays were performed in duplicate according to the manufacturers' instructions.

Using the above components, we calculated a continuous score representing a composite cardiovascular disease risk score and was derived by summing the standardized values [Z-score $=$ (participant's value - mean value of the sample)/standard deviation)] by age and sex, waist circumference (WC), systolic blood pressure, triglycerides, HDL-C (inverted), and glucose. Participants above 1 standard deviation (SD) of this score were classified as having a high cardiovascular risk.

\subsection{Pubertal Stage}

Pubertal stage (breast and pubic hair development for girls, genital and pubic hair development for boys; ranging from stage I to V) was self-assessed by the participants according to the classification of the criteria of Tanner and Whitehouse [33].

\subsection{Statistical Analysis}

Descriptive data are presented as means and standard deviations. Chi-squares for categorical variables and independent Two-tailed $t$-Tests for continuous variables were used to assess groups' differences. Analysis of covariance (ANCOVA) with Bonferroni post-hoc multiple comparison tests were used to assess the differences between the mean values of cardiovascular disease risk scores across the eight combined groups. Binary logistic regression models were constructed to verify the odds ratios (OR) of the combined groups of $\mathrm{CRF}, \mathrm{MF}$, and adherence to a MeDiet to predict a high cardiovascular risk. All the analyses were adjusted for, age, sex, pubertal stage, and country. Data were analyzed using SPSS (Statistical Package for the Social Sciences for Windows), version 23.0 SPSS Inc., Chicago, IL, USA. A $p$ value $<0.05$ denoted statistical significance.

\section{Results}

\subsection{Study Participants}

Descriptive characteristics of the participants according to CRF, MF, and MeDiet status are presented in Table 1. Participants in the Low MeDiet category had significantly lower glucose and HDL-cholesterol, and higher triglycerides, CRF, and MF ( $p<0.05$ for all) compared with those in the High MeDiet category. Both Low MF group and Low CRF groups showed significantly higher body mass index (BMI), WC, triglycerides, and lower HDL-C compared with their peers ( $p<0.05$ for all). 
Table 1. Characteristics of participants (mean (standard deviation (SD)) or frequency (\%)).

\begin{tabular}{|c|c|c|c|c|c|c|}
\hline Characteristics & $\begin{array}{l}\text { Low MeDiet } \\
(n=2115)\end{array}$ & $\begin{array}{l}\text { High MeDiet } \\
\quad(n=362)\end{array}$ & $\begin{array}{l}\text { Low MF } \\
(n=828)\end{array}$ & $\begin{array}{l}\text { High MF } \\
(n=1649)\end{array}$ & $\begin{array}{l}\text { Low CRF } \\
(n=982)\end{array}$ & $\begin{array}{l}\text { High CRF } \\
(n=1495)\end{array}$ \\
\hline Age (year) & $14.2(1.5)$ & $14.1(1.6)$ & $14.2(1.5)$ & $14.2(1.5)$ & $14.6(1.5)$ & $14.1(1.5)$ \\
\hline BMI $\left(\mathrm{kg} \mathrm{m}^{2}\right)$ & $20.3(3.0)$ & $21.0(3.7)$ & $21.7(3.7)^{b}$ & $19.9(3.1)$ & $21.2(3.5)^{c}$ & $20.0(2.7)$ \\
\hline Waist circumference $(\mathrm{cm})$ & $66.8(7.6)^{\mathrm{a}}$ & $70.8(10.1)$ & $69.8(9.6)^{\mathrm{b}}$ & $66.2(7.1)$ & $68.7(9.2)^{c}$ & $66.5(7.5)$ \\
\hline Pubertal status A: $\leq \mathrm{III} / \mathrm{IV} / \mathrm{V}(\%)$ & $48.0 / 44.7 / 8.3$ & $44.7 / 48.8 / 10.5$ & $51.0 / 41.2 / 7.8$ & $46.7 / 44.1 / 9.2$ & $48.1 / 42.1 / 9.8$ & $48.2 / 43.8 / 8.1$ \\
\hline Pubertal status B: $\leq \mathrm{III} / \mathrm{IV} / \mathrm{V}(\%)$ & $48.6 / 43.4 / 8.0$ & $40.6 / 43.1 / 16.3$ & $51.3 / 41.7 .7$ & $46.4 / 43.0 / 10.5$ & $49.2 / 42.0 / 8.8$ & $47.4 / 43.0 / 9.7$ \\
\hline HDL-Cholesterol (mg/dL) & $47.1(12.1)^{\mathrm{a}}$ & $52.0(12.2)$ & $45.6(11.2)^{b}$ & $49.0(12.6)$ & $46.4(11.9)^{\mathrm{c}}$ & $48,8(12.5)$ \\
\hline Triglycerides (mg/dL) & $87.9(42.1)^{\mathrm{a}}$ & $76.6(37.7)$ & $93.7(47.6)^{\mathrm{b}}$ & $82.5(37.9)$ & $88.7(42.8)^{\mathrm{c}}$ & $84.6(40.9)$ \\
\hline Glucose (mg/dL) & $83.0(15.1)^{\mathrm{a}}$ & $86.4(12.3)$ & $82.7(15.0)$ & $83.4(14.9)$ & $83.0(15.6)$ & $83.3(14.5)$ \\
\hline Systolic Blood Pressure $(\mathrm{mm} \mathrm{Hg})$ & $113.1(13.1)$ & $116.5(13.8)$ & $114.1(13.4)$ & $113.3(13.1)$ & $113.5(13.4)$ & $113.7(13.7)$ \\
\hline $\mathrm{CRF}-\mathrm{VO}_{2} \max (\mathrm{mL} / \mathrm{kg} / \mathrm{min})$ & $39.3(5.7)^{\mathrm{a}}$ & $42.1(6.4)$ & $37.3(5.1)^{b}$ & $40.9(5.9)$ & - & - \\
\hline Muscular Fitness Score & $-0.8(1.5)^{\mathrm{a}}$ & $0.4(1.7)$ & - & - & $-0.6(1.4)^{c}$ & $0.4(1.5)$ \\
\hline
\end{tabular}

Data are means ( \pm standard deviation) or frequencies (\%) ${ }^{\text {a }}$ Significantly different from High MedDiet $(p<0.05),{ }^{\text {b }}$ Significantly different from High MF ( $\left.p<0.05\right),{ }^{\mathrm{c}}$ Significantly different from High CRF $(p<0.05)$-Chi-square for categorical variables and independent Two-tailed $t$-Tests for continuous variable. BMI: Body mass index; MeDiet: Adherence to the Mediterranean diet; MF: muscular fitness; CRF: Cardiorespiratory fitness; Pubertal stage-A—breast development in girls; genital development in boys. Pubertal stage-B - pubic hair development. 
3.2. Relationship between Cardiovascular Risk Scores across Combined Groups of Adherence to a MeDiet, Cardiorespiratory Fitness, and Muscular Fitness

Figure 1 shows the differences in the cardiovascular risk score through the eight exclusive created groups according to the MeDiet, MF, and CRF status. Adolescents classified as having a High-MeDiet and HighMF/HighCRF, as well as the Low-MeDiet and with HighMF/HighCRF group, had, on average, the lowest cardiovascular risk score. In addition, the adolescents classified as having a High-MeDiet and LowMF/LowCRF had, on average, the highest mean values of the cardiovascular risk score $\left(\mathrm{F}_{(7,2436)}=15.6 ; p<0.001\right)$.

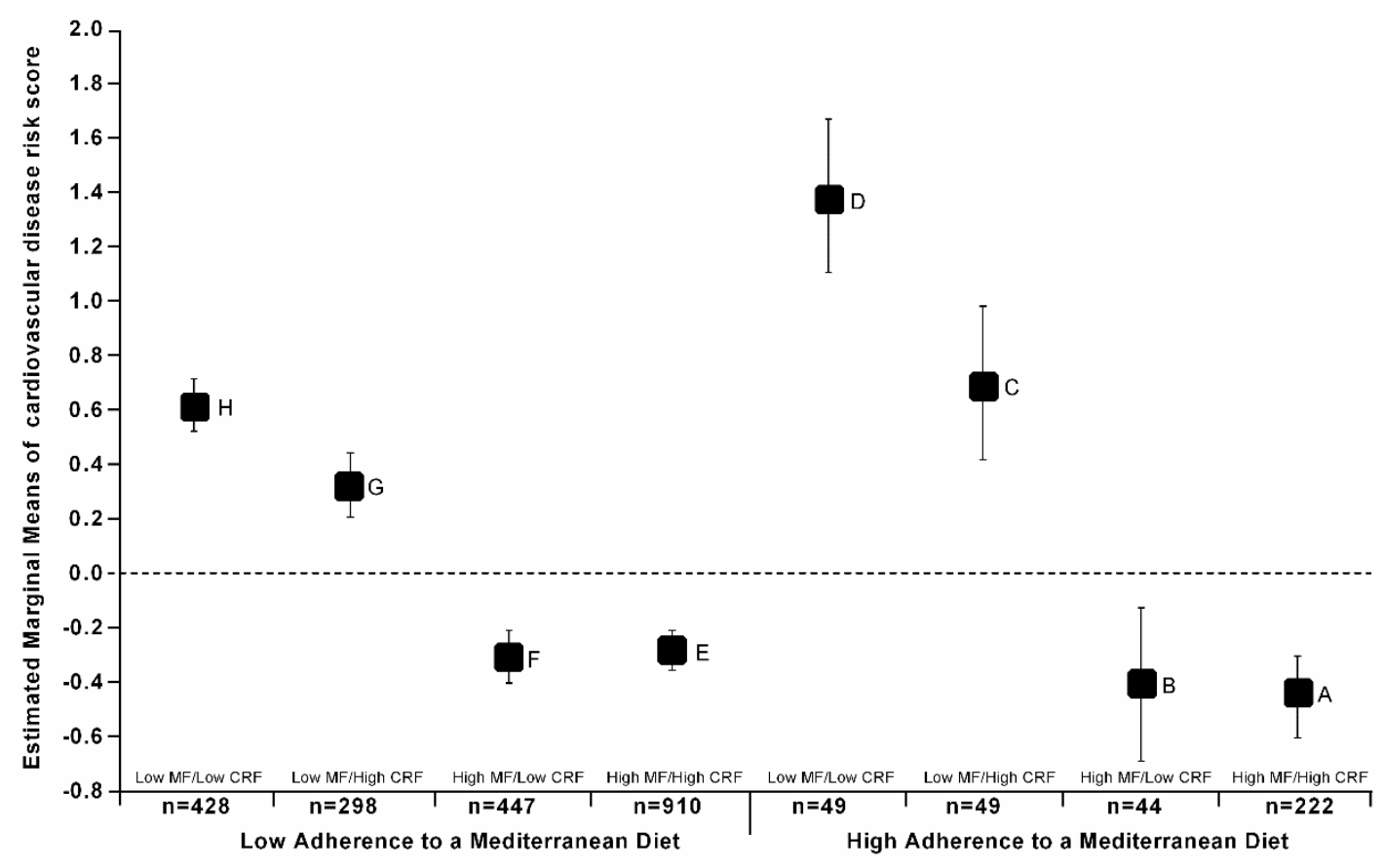

Figure 1. Mean values of cardiovascular risk score through the groups of adherence to a MedDiet (Low adherence vs. High adherence), cardiorespiratory fitness (Low CRF vs. High CRF), and muscular fitness (Low MF vs. High CRF). Bars represent adjusted means and 95\% confidence intervals, for age, sex, pubertal stage and country, as confounders. $A \neq(H-G-D-C) ; B \neq(D) ; C \neq(F-E-A)$; $\mathrm{D} \neq(\mathrm{G}-\mathrm{F}-\mathrm{E}-\mathrm{B}-\mathrm{A}) ; \mathrm{E} \neq(\mathrm{H}-\mathrm{G}-\mathrm{D}-\mathrm{C}) ; \mathrm{F} \neq(\mathrm{H}-\mathrm{G}-\mathrm{D}-\mathrm{C}) ; \mathrm{G} \neq(\mathrm{F}-\mathrm{E}-\mathrm{D}-\mathrm{A}) ;$ $\mathrm{H} \neq(\mathrm{F}-\mathrm{E}-\mathrm{A}) . p<0.04$ for all.

3.3. Association between High Cardiovascular Risk by Adherence to a MeDiet, Cardiorespiratory Fitness, and Muscular Fitness Categories

Binary logistic regression analysis showed that participants with a High-MeDiet and LowMF/LowCRF had the highest odds of having a high cardiovascular risk (OR $=7.1$; 95\% CI: 3.4-15.1; $p<0.001$ ), followed by the Low-MeDiet and LowMF/LowCRF group (OR = 3.7; 95\% CI: 2.2-6.3; $p<0.001$ ), High-MeDiet and HighMF/LowCRF group (OR = 3.1; 95\% CI: 1.4-7.0; $p=0.006$ ), and the Low-MeDiet and LowMF/HighCRF group (OR = 2.5; 95\% CI: 1.5-4.4; $p=0.002)$, when compared to those with High-MeDiet and HighMF/ I HighCRF, after adjustments for potential confounders (Table 2). 
Table 2. Odds ratio of high cardiovascular risk by adherence to a Mediterranean Diet, cardiorespiratory fitness, and muscular fitness categories.

\begin{tabular}{ccccc}
\hline \multirow{2}{*}{ Parameter } & $\begin{array}{c}\text { OR Unadjusted } \\
\mathbf{( 9 5 \%} \mathbf{C I})\end{array}$ & $p$-Value & $\begin{array}{c}\text { OR Adjusted } \\
\mathbf{( 9 5 \% ~ C I ) ~}\end{array}$ & $p$-Value \\
\hline $\begin{array}{c}\text { High-MeDiet } \\
\text { HighMF/HighCRF }\end{array}$ & 1.0 & - & 1.0 & - \\
\hline $\begin{array}{c}\text { High-MeDiet } \\
\text { HighMF/LowCRF }\end{array}$ & $2.0(0.8-4.9)$ & 0.109 & $1.8(0.7-4.0)$ & 0.165 \\
\hline $\begin{array}{c}\text { High-MeDiet } \\
\text { LowMF/HighCRF }\end{array}$ & $2.5(1.1-5.6)$ & 0.023 & $3.1(1.4-7.0)$ & 0.006 \\
\hline $\begin{array}{c}\text { High-MeDiet } \\
\text { LowMF/LowCRF }\end{array}$ & $6.5(3.1-13.3)$ & $<0.001$ & $7.1(3.4-15.1)$ & $<0.001$ \\
\hline $\begin{array}{c}\text { Low-MeDiet } \\
\text { HighMF/HighCRF }\end{array}$ & $0.9(0.6-1.5)$ & 0.897 & $1.3(0.7-2.1)$ & 0.346 \\
\hline $\begin{array}{c}\text { Low-MeDiet } \\
\text { HighMF/LowCRF }\end{array}$ & $1.1(0.6-1.9)$ & 0.611 & $1.6(0.8-2.7)$ & 0.112 \\
\hline $\begin{array}{c}\text { Low-MeDiet } \\
\text { LowMF/HighCRF }\end{array}$ & $1.5(0.9-2.6)$ & 0.113 & $2.5(1.5-4.4)$ & 0.002 \\
\hline $\begin{array}{c}\text { Low-MeDiet } \\
\text { LowMF/LowCRF }\end{array}$ & $2.5(1.5-4.1)$ & $<0.001$ & $3.7(2.2-6.3)$ & $<0.001$ \\
\hline
\end{tabular}

OR, odds ratios; CI, confidence intervals; 1, reference category. * Adjusted for age, sex, pubertal stage, country. MF, Muscular Fitness. CRF, Cardiorespiratory Fitness.

\section{Discussion}

In the current study, cardiovascular risk factors, adherence to the MeDiet, MF, and CRF were examined in 2444 adolescents. We found that the combination of low MF and low CRF cumulatively presented the highest cardiovascular disease risk regardless of the MeDiet status. This association persisted after adjustment for age, sex, pubertal stage, and country among participants in the LowMF/HighCRF group and independent of MeDiet status.

Adherence to a healthy dietary pattern, MF, and CRF are critical, yet modifiable, determinants for adolescents' health-related behaviors. Several studies have reported the beneficial health effects of both MF $[28,34,35]$ and CRF $[16,19,36]$, as well as adherence to a MeDiet [23,24]. However, to our knowledge, there are no data about the combined effect of adherence to a MeDiet, MF, and CRF on cardiovascular risk factors in adolescents.

Indeed, optimal adherence to a Mediterranean dietary pattern is associated with a significantly lower risk of overall mortality, mortality from cardiovascular diseases, incidence of dementia, and mortality from cancer [23]. In adolescents, adherence to a MeDiet has been associated with a healthier metabolic profile [24]. Likewise, our findings showed that the optimal MeDiet group had, on average, an improved metabolic profile when compared with the Low MeDiet group. However, in our combined analysis, the findings suggest that the harmful consequences ascribed to the effect of both low MF and CRF combined could not be counteracted by maintaining of an optimal adherence to a MeDiet.

Paradoxically, it seems that an optimal adherence of MeDiet, in the presence of both low levels of MF and CRF, may increase cardiometabolic risk. Indeed, a study in Portuguese adolescents showed that fit participants had a lower metabolic risk score, independent of their adherence to a healthy dietary pattern, suggesting that high CRF may overcome the deleterious effects of low adherence to a healthy dietary pattern in adolescents [37]. In addition, previous studies in youth have shown that the MeDiet may have some nutrients, such as sodium and fatty acids, which may contribute, at least in part, to our findings [38].

There is an unequivocal association between low CRF levels and cardiometabolic risk factors in adolescents [36]. Presently, a growing body of evidence has also demonstrated the benefits of ideal levels of MF on metabolic health [34]. Recently, Fraser and colleagues [18], in a longitudinal study 
of 20 years, demonstrated that childhood MF and CRF were associated with beta cell function and insulin resistance in adulthood. Previously, our group has shown that CRF $[15,16,39]$ and MF $[17,20,28]$ were inversely associated with metabolic risk factors. However, in these studies, the analysis of the combined effect of adherence to a MeDiet and both fitness components on cardiometabolic health was not possible due to the small number of adolescents in the groups. In the current study using pooled analysis, we could show that the Low MedDiet/LowMF/HighCRF group, as well as the optimal MedDiet/LowMF/HighCRF group, might still present a poor cardiometabolic profile.

Evidence suggests that low MF may be, at least, as important as body composition, [40] and, in some [41,42], but not all studies [43], as important as CRF in determining cardiometabolic risk in adolescents. Indeed, low MF is emerging in the literature as a predictor of mortality and premature death $[35,44]$. More recently, the potential protective effects of high MF on cardiometabolic health have been found in adults [13], with the suggestion that MF may protect against CVD independently of CRF [12]. Our findings also showed for the first time that adolescents with low MF may display an unhealthy cardiometabolic profile, regardless of CRF and adherence to a MeDiet. In fact, accumulated evidence has suggested that MF might have a stronger influence on the cardiometabolic profile [13,35], although both CRF and MF have showed an independent protection against cardiovascular disease and all-cause mortality in apparently healthy populations [12-14].

Our findings do support the current literature, which shows both MF and CRF as important markers of cardiometabolic health in youth and adds new information showing the potential health effects of healthy MF and CRF levels to an adherence to a MeDiet. The present study has an important point of view from the public health perspective, since healthy behaviors do not always come together, therefore, active adolescents may have an optimal adherence to a healthy dietary pattern and high levels of physical fitness, but also the opposite $[45,46]$. Thus, even if an adolescent has an optimal adherence to a MeDiet, it seems that unhealthy levels of physical fitness may increase cardiometabolic risk. These findings highlight the relevance of physical fitness and support the current physical activity recommendations for youths, which include aerobic exercise and muscle strengthening activities [5].

Limitations of our study include its cross-sectional design, which does not allow us to draw any conclusions on the causal direction of the associations. Additionally, the Kidmed questionnaire has inherent limitations of precision due to its reliance on self-reported data, and the choice of research method precluded independent verification [47].

The strengths of our study include the consideration of a fairly large sample size and standardised methods used to collect the data. In addition, the novelty of the analysis of the combined associations of three important health factors on adolescents' cardiometabolic health.

\section{Conclusions}

On the basis of our results and by accounting for all the limitations inherent in our study, we show that the combination of low MF and low CRF cumulatively presented the highest cardiovascular disease risk regardless of the MedDiet status. Therefore, these findings suggest that the combination of MF and CRF components may be beneficial to adolescents' cardiometabolic profile, independent of MeDiet behaviour.

Author Contributions: C.A.-S., R.R.-V., J.E.C.-B., R.S., R.R., C.M., L.L. and J.M. conceived and designed the study; A.M. and A.G.-H. contributed to the data analysis; R.R.-V. and C.A.-S. analyzed the data and wrote the paper. All authors read and approved the final manuscript.

Funding: The doctoral research grant to C.A.-S. from Brazilian government by CAPES (Coordination of Improvement of Higher Education Personnel) (Proc: 9588-13-2). The Research Centre on Physical Activity Health and Leisure (CIAFEL) is supported by UID/DTP/00617/2013 (FCT). The research grant to R.S. from the Australian Research Council (DE150101921). This research was funded by Instituto Colombiano para el Desarrollo de la Ciencia y la Tecnología "Francisco José de Caldas" COLCIENCIAS grant number Contract No 671-2014 Code 122265743978.

Acknowledgments: The authors thank all of the adolescents for their dedication and contribution to the research.

Conflicts of Interest: The authors declare no conflict of interest. 


\section{Abbreviations}

The following abbreviations are used in this manuscript:

$\begin{array}{ll}\text { BMI } & \text { Body mass index } \\ \text { CRF } & \text { Cardiorespiratory fitness } \\ \text { CVD } & \text { Cardiovascular disease } \\ \text { HDL } & \text { High-density lipoprotein cholesterol } \\ \text { MedDiet } & \text { Adherence to Mediterranean Diet } \\ \mathrm{MF} & \text { Muscular Fitness } \\ \mathrm{TC} & \text { Total cholesterol } \\ \mathrm{VO}_{2} \mathrm{max} & \text { Maximum oxygen consumption } \\ \mathrm{WC} & \text { Waist circumference }\end{array}$

\section{References}

1. Balagopal, P.B.; De Ferranti, S.D.; Cook, S.; Daniels, S.R.; Gidding, S.S.; Hayman, L.L.; McCrindle, B.W.; Mietus-Snyder, M.L.; Steinberger, J.; American Heart Association Committee on Atherosclerosis Hypertension and Obesity in Youth of the Council on Cardiovascular Disease in the Young; et al. Nontraditional risk factors and biomarkers for cardiovascular disease: Mechanistic, research, and clinical considerations for youth: A scientific statement from the American Heart Association. Circulation 2011, 123, 2749-2769. [CrossRef] [PubMed]

2. Friend, A.; Craig, L.; Turner, S. The Prevalence of Metabolic Syndrome in Children: A Systematic Review of the Literature. Metab. Syndr. Relat. Disord. 2013, 11, 71-80. [CrossRef] [PubMed]

3. Alberti, S.G.; Zimmet, P. The IDF Consensus Definition of the Metabolic Syndrome in Children and Adolescents; International Diabetes Federation: Brussels, Belgium, 2007; p. 24.

4. Andersen, L.B.; Lauersen, J.B.; Brønd, J.C.; Anderssen, S.A.; Sardinha, L.B.; Steene-Johannessen, J.; McMurray, R.G.; Barros, M.V.G.; Kriemler, S.; Møller, N.C.; et al. A New Approach to Define and Diagnose Cardiometabolic Disorder in Children. J. Diabetes Res. 2015, 2015, 539835. [CrossRef] [PubMed]

5. WHO. 2008-2013 Action Plan for the Global Strategy for the Prevention and Control of Noncommunicable Diseases; Geneva World Heal Organ: Geneva, Switzerland, 2008.

6. Okubo, H.; Crozier, S.R.; Harvey, N.C.; Godfrey, K.M.; Inskip, H.M.; Cooper, C.; Robinson, S.M. Diet quality across early childhood and adiposity at 6 years: The Southampton Women's Survey. Int. J. Obes. 2015, 39, 1456-1462. [CrossRef] [PubMed]

7. Storey, K.E.; Hanning, R.M.; Lambraki, I.A.; Driezen, P.; Fraser, S.N.; McCargar, L.J. Determinants of Diet quality among Canadian adolescents. Can. J. Diet. Pract. Res. 2009, 70, 58-65. [CrossRef] [PubMed]

8. WHO. Diet, Nutrition and the Prevention of Chronic Diseases; World Health Organ Tech Rep Ser 2003, 916, i-viii-1-149-Backcover; WHO: Geneva, Switzerland, 2003.

9. Kohl, H.W.; Craig, C.L.; Lambert, E.V.; Inoue, S.; Alkandari, J.R.; Leetongin, G.; Kahlmeier, S. The pandemic of physical inactivity: Global action for public health. Lancet 2012, 380, 294-305. [CrossRef]

10. Cooper, A.R.; Goodman, A.; Page, A.S.; Sherar, L.B.; Esliger, D.W.; van Sluijs, E.M.; Andersen, L.B.; Anderssen, S.; Cardon, G.; Davey, R.; et al. Objectively measured physical activity and sedentary time in youth: The International children's accelerometry database (ICAD). Int. J. Behav. Nutr. Phys. Act. 2015, 12, 113. [CrossRef] [PubMed]

11. Neill, S.O.; Driscoll, L.O.; O'Neill, S.; O’Driscoll, L. Metabolic syndrome: A closer look at the growing epidemic and its associated pathologies. Obes. Rev. 2015, 16, 1-12. [CrossRef] [PubMed]

12. Kodama, S.; Saito, K.; Tanaka, S.; Maki, M.; Yachi, Y.; Asumi, M.; Sugawara, A.; Totsuka, K.; Shimano, H.; Ohashi, Y.; et al. Cardiorespiratory fitness as a quantitative predictor of all-cause mortality and cardiovascular events in healthy men and women. J. Am. Med. Assoc. 2009, 301, 2024-2035. [CrossRef] [PubMed]

13. García-Hermoso, A.; Cavero-Redondo, I.; Ramírez-Vélez, R.; Ruiz, J.; Ortega, F.B.; Lee, D.-C.; Martínez-Vizcaíno, V. Muscular strength as a predictor of all-cause mortality in apparently healthy population: A systematic review and meta-analysis of data from approximately 2 million men and women. Arch. Phys. Med. Rehabil. 2018. [CrossRef] [PubMed]

14. Hogstrom, G.; Nordstrom, A.; Nordstrom, P. High aerobic fitness in late adolescence is associated with a reduced risk of myocardial infarction later in life: A nationwide cohort study in men. Eur. Heart J. 2014, 35, 3133-3140. [CrossRef] [PubMed] 
15. Agostinis-Sobrinho, C.; Ruiz, J.R.; Moreira, C.; Abreu, S.; Lopes, L.; Oliveira-Santos, J.; Mota, J.; Santos, R. Cardiorespiratory Fitness and Blood Pressure: A Longitudinal Analysis. J. Pediatr. 2018, 192, 130-135. [CrossRef] [PubMed]

16. Agostinis-Sobrinho, C.C.A.; Ruiz, J.R.J.; Moreira, C.; Abreu, S.; Luís, L.; Oliveira-Santos, J.; Mota, J.; Santos, R. Cardiorespiratory fitness and inflammatory profile on cardiometabolic risk in adolescents from the LabMed Physical Activity Study. Eur. J. Appl. Physiol. 2017, 117, 2271-2279. [CrossRef] [PubMed]

17. Agostinis-Sobrinho, C.A.; Ramirez-Velez, R.; Garcia-Hermoso, A.; Moreira, C.; Lopes, L.; Oliveira-Santos, J.; Abreu, S.; Mota, J.; Santos, R. Low-grade inflammation and muscular fitness on insulin resistance in adolescents: Results from LabMed Physical Activity Study. Pediatr. Diabetes 2017, 19, 429-435. [CrossRef] [PubMed]

18. Fraser, B.J.; Blizzard, L.; Schmidt, M.D.; Juonala, M.; Dwyer, T.; Venn, A.J.; Magnussen, C.G. Childhood cardiorespiratory fitness, muscular fitness and adult measures of glucose homeostasis. J. Sci. Med. Sport 2018. [CrossRef] [PubMed]

19. Ruiz, J.R.; Cavero-Redondo, I.; Ortega, F.B.; Welk, G.J.; Andersen, L.B.; Martinez-Vizcaino, V. Cardiorespiratory fitness cut points to avoid cardiovascular disease risk in children and adolescents; what level of fitness should raise a red flag? A systematic review and meta-analysis. Br. J. Sports Med. 2016, 50, 1451-1458. [CrossRef] [PubMed]

20. Agostinis-Sobrinho, C.; Brand, C.; Moreira, C.; Lopes, L.; Oliveira-Santos, J.; Silva, P.; Reis Gaya, A.; Gaya, A.; Mota, J.; Santos, R.; et al. Muscular fitness, Southern European Atlantic Diet and inflammation in adolescents. Azorean Physical Activity and Health Study II. Eur. J. Sport Sci. 2018, 18, 104-111. [CrossRef] [PubMed]

21. Grøntved, A.; Ried-Larsen, M.; Ekelund, U.; Froberg, K.; Brage, S.; Andersen, L.B. Independent and combined association of muscle strength and cardiorespiratory fitness in youth with insulin resistance and $\beta$-cell function in young adulthood: The european youth heart study. Diabetes Care 2013, 36, 2575-2581. [CrossRef] [PubMed]

22. Morikawa, S.Y.; Fujihara, K.; Hatta, M.; Osawa, T.; Ishizawa, M.; Yamamoto, M.; Furukawa, K.; Ishiguro, H.; Matsunaga, S.; Ogawa, Y.; et al. Relationships among cardiorespiratory fitness, muscular fitness, and cardiometabolic risk factors in Japanese adolescents: Niigata screening for and preventing the development of non-communicable disease study-Agano (NICE EVIDENCE Study-Agano) 2. Pediatr. Diabetes 2017, 19, 593-602. [CrossRef] [PubMed]

23. Sofi, F.; Cesari, F.; Abbate, R.; Gensini, G.F.; Casini, A. Adherence to Mediterranean diet and health status: Meta-analysis. BMJ 2008, 337, a1344. [CrossRef] [PubMed]

24. Arouca, A.; Michels, N.; Moreno, L.A.; González-Gil, E.M.; Marcos, A.; Gómez, S.; Díaz, L.E.; Widhalm, K.; Molnár, D.; Manios, Y.; et al. Associations between a Mediterranean diet pattern and inflammatory biomarkers in European adolescents. Eur. J. Nutr. 2017. [CrossRef] [PubMed]

25. Ramírez-Vélez, R.; Morales, O.; Peña-lbagon, J.C.; Palacios-López, A.; Prieto-Benavides, D.H.; Vivas, A.; Correa-Bautista, J.E.; Lobelo, F.; Alonso-Martínez, A.M.; Izquierdo, M. Normative Reference Values for Handgrip Strength in Colombian Schoolchildren. J. Strength Cond. Res. 2017, 31, 217-226. [CrossRef] [PubMed]

26. Ramírez-Vélez, R.; Rodrigues-Bezerra, D.; Correa-Bautista, J.E.; Izquierdo, M.; Lobelo, F. Reliability of health-related physical fitness tests among Colombian children and adolescents: The Fuprecol study. PLoS ONE 2015, 10, e0140875. [CrossRef] [PubMed]

27. Agostinis-Sobrinho, C.; Santos, R.; Moreira, C.; Abreu, S.; Lopes, L.; Oliveira-Santos, J.; Rosário, R.; Póvoas, S.; Mota, J. Association between serum adiponectin levels and muscular fitness in Portuguese adolescents: LabMed Physical Activity Study. Nutr. Metab. Cardiovasc. Dis. 2016, 6, 517-524. [CrossRef] [PubMed]

28. Agostinis-Sobrinho, C.A.; Moreira, C.; Abreu, S.; Lopes, L.; Sardinha, L.B.; Oliveira-Santos, J.; Oliveira, A.; Mota, J.; Santos, R. Muscular fitness and metabolic and inflammatory biomarkers in adolescents: Results from LabMed Physical Activity Study. Scand. J. Med. Sci. Sports 2016, 27, 1873-1880. [CrossRef] [PubMed]

29. Serra-Majem, L.; Ribas, L.; Ngo, J.; Ortega, R.M.; García, A.; Pérez-Rodrigo, C.; Aranceta, J. Food, youth and the Mediterranean diet in Spain. Development of KIDMED, Mediterranean Diet Quality Index in children and adolescents. Public Health Nutr. 2004, 7, 931-935. [CrossRef] [PubMed]

30. Leger, L.A.; Mercier, D.; Gadoury, C.; Lambert, J. The multistage $20 \mathrm{~m}$ shuttle run test for aerobic fitness. J. Sport Sci. 1988, 6, 93-101. [CrossRef] [PubMed]

31. Ruiz, J.R.; Castro-Piñero, J.; España-Romero, V.; Artero, E.G.; Ortega, F.B.; Cuenca, M.M.; Jimenez-Pavón, D.; Chillón, P.; Girela-Rejón, M.J.; Mora, J.; et al. Field-based fitness assessment in young people: The ALPHA health-related fitness test battery for children and adolescents. Br. J. Sports Med. 2011, 45, 518-524. [CrossRef] [PubMed] 
32. Ramírez-Vélez, R.; García-Hermoso, A.; Agostinis-Sobrinho, C.; Mota, J.; Santos, R.; Correa-Bautista, J.E.J.E.; Peña-Guzmán, C.A.; Domínguez-Sánchez, M.A.; Schmidt-RioValle, J.; González-Jiménez, E. Pubertal stage, body mass index, and cardiometabolic risk in children and adolescents in Bogotá, Colombia: The cross-sectional fuprecol study. Nutrients 2017, 9, 644. [CrossRef] [PubMed]

33. Tanner, J.M.; Whitehouse, R.H. Clinical longitudinal standards for height, weight, height velocity, weight velocity, and stages of puberty. Arch. Dis. Child. 1976, 51, 170-179. [CrossRef] [PubMed]

34. Smith, J.J.; Eather, N.; Morgan, P.J.; Plotnikoff, R.C.; Faigenbaum, A.D.; Lubans, D.R. The health benefits of muscular fitness for children and adolescents: A systematic review and meta-analysis. Sports Med. 2014, 44, 1209-1223. [CrossRef] [PubMed]

35. Ortega, F.B.; Silventoinen, K.; Tynelius, P.; Rasmussen, F. Muscular strength in male adolescents and premature death: Cohort study of one million participants. BMJ 2012, 345, e7279. [CrossRef] [PubMed]

36. Ortega, F.B.; Ruiz, J.R.; Castillo, M.J.; Sjöström, M. Physical fitness in childhood and adolescence: A powerful marker of health. Int. J. Obes. (Lond.) 2008, 32, 1-11. [CrossRef] [PubMed]

37. Moreira, C.; Santos, R.; Moreira, P.; Lobelo, F.; Ruiz, J.R.; Vale, S.; Santos, P.C.; Abreu, S.; Mota, J. Cardiorespiratory fitness is negatively associated with metabolic risk factors independently of the adherence to a healthydietary pattern. Nutr. Metab. Cardiovasc. Dis. 2013, 23, 670-676. [CrossRef] [PubMed]

38. Magriplis, E.; Farajian, P.; Pounis, G.D.; Risvas, G.; Panagiotakos, D.B.; Zampelas, A. High sodium intake of children through "hidden" food sources and its association with the Mediterranean diet: The GRECO study. J. Hypertens. 2011, 29, 1069-1076. [CrossRef] [PubMed]

39. Garcia-Hermoso, A.; Agostinis-Sobrinho, C.; Mota, J.; Santos, R.M.; Correa-Bautista, J.E.; Ramírez-Vélez, R. Adiposity as a Full Mediator of the Influence of Cardiorespiratory Fitness and Inflammation in Schoolchildren: The FUPRECOL Study. Nutr. Metab. Cardiovasc. Dis. 2017, 27, 525-533. [CrossRef] [PubMed]

40. García-Hermoso, A.; Carrillo, H.A.; González-Ruóz, K.; Vivas, A.; Triana-Reina, H.R.; Martoínez-Torres, J.; Prieto-Benavidez, D.H.; Correa-Bautista, J.E.; Ramos-Sepúlveda, J.A.; Villa-González, E.; et al. Fatness mediates the influence of muscular fitness on metabolic syndrome in Colombian collegiate students. PLoS ONE 2017, 12, e0173932. [CrossRef] [PubMed]

41. Cohen, D.D.; Gómez-Arbeláez, D.; Camacho, P.A.; Pinzon, S.; Hormiga, C.; Trejos-Suarez, J.; Duperly, J.; Lopez-Jaramillo, P. Low muscle strength is associated with metabolic risk factors in Colombian children: The ACFIES study. PLoS ONE 2014, 9, e93150. [CrossRef] [PubMed]

42. Artero, E.G.; Ruiz, J.R.; Ortega, F.B.; España-Romero, V.; Vicente-Rodríguez, G.; Molnar, D.; Gottrand, F.; González-Gross, M.; Breidenassel, C.; Moreno, L.A.; et al. Muscular and cardiorespiratory fitness are independently associated with metabolic risk in adolescents: The HELENA study. Pediatr. Diabetes 2011, 12, 704-712. [CrossRef] [PubMed]

43. Steene-Johannessen, J.; Anderssen, S.A.; Kolle, E.; Andersen, L.B. Low muscle fitness is associated with metabolic risk in youth. Med. Sci. Sport Exerc. 2009, 41, 1361-1367. [CrossRef] [PubMed]

44. Volaklis, K.A.; Halle, M.; Meisinger, C. Muscular strength as a strong predictor of mortality: A narrative review. Eur. J. Intern. Med. 2015, 26, 303-310. [CrossRef] [PubMed]

45. Ottevaere, C.; Huybrechts, I.; Benser, J.; De Bourdeaudhuij, I.; Cuenca-Garcia, M.; Dallongeville, J.; Zaccaria, M.; Gottrand, F.; Kersting, M.; Rey-López, J.P. Clustering patterns of physical activity, sedentary and dietary behavior among European adolescents: The HELENA study. BMC Public Health 2011, 11, 328. [CrossRef] [PubMed]

46. Jago, R.; Ness, A.R.; Emmett, P.; Mattocks, C.; Jones, L.; Riddoch, C.J. Obesogenic diet and physical activity: Independent or associated behaviours in adolescents? Public Health Nutr. 2010, 13, 673-681. [CrossRef] [PubMed]

47. Della Corte, C.; Mosca, A.; Vania, A.; Alterio, A.; Iasevoli, S.; Nobili, V. Good Adherence to Mediterranean Diet reduces the risk to develop NASH and diabetes in pediatric patients with obesity: The results of an Italian Study. Nutrition 2017, 39-40, 8-14. [CrossRef] [PubMed]

(C) 2018 by the authors. Licensee MDPI, Basel, Switzerland. This article is an open access article distributed under the terms and conditions of the Creative Commons Attribution (CC BY) license (http:/ / creativecommons.org/licenses/by/4.0/). 